Pacific Journal of Mathematics

LOOPS WITH TRANSITIVE AUTOMORPHISM GROUPS 


\title{
LOOPS WITH TRANSITIVE AUTOMORPHISM GROUPS
}

\author{
R. H. BRUCK
}

1. Introduction. Every automorphism of an additive loop $1 L$ maps 0 upon 0 . The automorphism group $A(L)$ of $L$ will be called transitive if $A(L)$ is transitive on the nonzero elements of $L$. It is readily deducer from work of L. J. Paige [4] and 1'. T. Batenian [3] that, for every cardinal number $n$, there exists a loop $L$ of cardinal number $n$ with a transitive automorphism group. We shall demonstrate that (aside from the obvious exceptions) such a loop $L$ must be simple, that is, its only normal subloops must be 0 and $L$, if it satisfies the following ascending chain dition:

(C) If $N_{1} \subset N_{2} \subset N_{3} \subset \cdots$ is an ascending chain of normal subloops of the loop $L$, there exists an integer $i$ such that $N_{i}=V_{i+1}$.

2. Theorem. ife shall establish the following result.

THEOREM I. In additive loop $I$. which satisfies (C) and has a transitive automorphism group is either (i) a simple loop or (ii) a finite abelian p-group of type $(p, p, \cdots, p)$.

Proof. For each nonzero $a$ of $L$, denote by $M(a)$ the smallest normal subloop of $L$ which contains $a$.

(1) The subloop $\|($ a) has a transitive automorphism group and is a minimal normal subloop of $L$. If $b \neq 0$ is in $M(a)$, then there exists $\theta \in A(L)$ such that ${ }_{a} \Theta=b$. Since $\theta$ maps normal subloops upon normal subloops, we have $M(a) \theta=$ $M(b)$. Since $b \in M(a)$, it follows that $M(b) \subset M(a)$. If $\phi=\theta^{-1}$, then $M(a)=$ $M(b) \phi \subset \|(a) \phi$, and, by induction, $M(a) \subset M(a) \phi \subset M(a) \phi^{2} \subset \cdots$. In view of $(\mathrm{C})$, we have $M(a) \phi^{i}=M(a) \phi^{i+1}$ for some integer $i$. Since $\phi$ is an automorphism of $L$, it follows that $M(a)=U(a) \phi^{-1}=H(a) \theta=M(b)$. Hence $\theta$ induces an automorphism of $M(a)$. This is enough to prove (1).

\footnotetext{
1 Readers unfamiliar with loop theory will get the sense of the paper if they read group in place of loop. The necessary loop the ory will be found in Baer $[1,2]$.

Pacific J. Math. 1 (1951), 481-483.
} 
(2) If $N$ is a normal subloop of $L$, then $N \cap M(a)=0$ or $H(a)$. This follows from the minimality of $M(a)$.

(3) The loop $L$ is a direct sum of a finite number $r$ of isomorphic simple subloops $M_{i}$; that is, $L=M_{1} \oplus M_{2} \oplus \cdots \oplus M_{r}$. If $a, b$ are nonzero elements of $L$, there exists $\theta \in A(L)$ such that $a \theta=b$. Then $V(a) \theta=M(b)$, showing that all the minimal normal subloops $M(a)$ are isomorphic. If $a_{1}$ is an arbitrary nonzero element of $L$, define $M_{1}=M\left(a_{1}\right)$. Now suppose that $H_{i}=M\left(a_{i}\right)$ has been defined, for $i=1,2, \cdots, s$, such that the (normal) subloop $N_{s}$ generated by the $U_{i}$ is the direct sum $N_{s}=M_{1} \oplus \cdots \oplus M_{s}$. Write $t=s+1$. If there exists a nonzero element $a_{t}$ of $L$ which is not in $N_{s}$, define $M_{t}=M\left(a_{t}\right)$. Then $N_{s} \cap M_{t}=0$, by (2), and hence $N_{t}=N_{s} \oplus H_{t}=M_{1} \oplus \cdots \oplus M_{t}$. In view of $(\mathrm{C})$, the strictly increasing chain $\therefore{ }_{r} \subset N_{2} \subset \cdots$ must be finite. 'Therefore $L=N_{r}$ for some integer $r$. If $M^{\prime}$ is a normal subloop of $M_{1}$, then $M^{\prime}$ is normal in $L$, by virtue of the direct decomposition. Hence, by (1), each $M_{i}$ is simple. This proves (3).

The center $Z(L)$ of a loop $L$ is a characteristic subloop and an abelian group. In view of (1), either $Z\left(M_{i}\right)=0$ or $Z\left(M_{i}\right)=M_{i}$. Hence, by (3), either (i') $Z(L)=0$ or ( $\left.\mathrm{ii}^{\prime}\right) L$ is a direct sum of isomorphic simple abelian groups. Since a simple abelian group is cyclic of prime order $p$, (ii') implies (ii) of Theorem 1. (Conversely, every finite abelian $p$-group of type $(p, p, \cdots, p)$ satisfies the hypotheses of the theorem.) In the case $\left(i^{\prime}\right)$, assume $r>1$ in (3). Since $Z(L)=0$, the decomposition (3) is unique. However, the nonzero element $c=a_{1}+a_{2}$ is in $M_{1} \oplus M_{2}$ but not in any of the $M_{i}$. Yet the proof of (3) shows that $M(c)$ could be chosen as the first factor in the direct decomposition of $L$, a contradiction. Therefore $r=1$, and we have (i). This completes the proof of Theorem 1 .

As the following (trivial) theorem shows, simple loops need not have transitive automorphism groups:

THEOREM 2. A finite simple group $G \neq 0$ with a transitive automorphism group is necessarily cyclic of prime order.

Proof. Every nonzero element of $G$ has the same order $p$, necessarily prime. Thus $G$ is a $p$-group, $Z(G) \neq 0, Z(G)=G$, and $G$ is cyclic of order $p$.

3. Remarks. The author does not know whether finiteness is necessary for the conclusion of Theorem 2 . 
The following is the nonabelian loop $L$ of lowest order with a transitive automornhisn group; it is realily verified that $A(L)$ is the (alternating) group of order 12 generated by $(12)(34)$ and (123):

\begin{tabular}{l|lllll}
+ & 0 & 1 & 2 & 3 & 4 \\
\hline 0 & 0 & 1 & 2 & 3 & 4 \\
1 & 1 & 0 & 3 & 4 & 2 \\
2 & 2 & 4 & 0 & 1 & 3 \\
3 & 3 & 2 & 4 & 0 & 1 \\
+ & 4 & 3 & 1 & 2 & 0
\end{tabular}.

REFERENCES

1. Reinhold Baer, The homomorphism theorems for loops, Amer. J. Math. 67 (1945), 450- 460 .

2. - Direct decompositions, Trans. Amer. Niath. Soc. 6: (1947), 62-98.

3. P. T. Bateman, A remark on infinite groups, Amer. Nath. Nonthly 57 (1950), 623-624.

4. L. J. Paige, Neofields, Duke Math. J. 16 (1949), 39-60.

UNIVERSITY OF MISCONSIN 



\section{PACIFIC JOURNAL OF MATHEMATICS}

EDITORS

\author{
M.M. SCHIFFER* \\ Stanford University \\ Stanford, California \\ E. HEWITT \\ University of Washington \\ Seattle 5, Washington
}

\author{
R.P. DILWORTH \\ California Institute of Technology \\ Pasadena 4, California \\ E.F. BECKENBACH** \\ University of California \\ Los Angeles 24, California
}

\section{ASSOCIATE EDITORS}

$\begin{array}{llll}\text { H. BUSEMANN } & \text { P.R. HALMOS } & \text { BØRGE JESSEN } & \text { J. J. STOKER } \\ \text { HERBERT FEDERER } & \text { HEINZ HOPF } & \text { PAUL LÉVY } & \text { E.G. STRAUS } \\ \text { MARSHALL HALL } & \text { R.D. JAMES } & \text { GEORGE PÓLYA } & \text { KÔSAKU YOSIDA }\end{array}$

\section{SPONSORS}

UNIVERSITY OF BRITISH COLUMBIA

UNIVERSITY OF SOUTHERN CALIFORNIA

CALIFORNIA INSTITUTE OF TECHNOLOGY

UNIVERSITY OF CALIFORNIA, BERKELEY

STANFORD RESEARCH INSTITUTE

UNIVERSITY OF CALIFORNIA, DAVIS

STANFORD UNIVERSITY

UNIVERSITY OF CALIFORNIA, LOS ANGELES

UNIVERSITY OF CALIFORNIA, SANTA BARBARA

WASHINGTON STATE COLLEGE

UNIVERSITY OF WASHINGTON

UNIVERSITY OF NEVADA

OREGON STATE COLLEGE

AMERICAN MATHEMATICAL SOCIETY

UNIVERSITY OF OREGON

HUGHES AIRCRAFT COMPANY

Mathematical papers intended for publication in the Pacific Journal of Mathematics should be typewritten (double spaced), and the author should keep a complete copy. Manuscripts may be sent to any. of the editors. Manuscripts intended for the outgoing editors should be sent to their successors. All other communications to the editors should be addressed to the managing editor, E.G. Straus, at the University of California Los Angeles 24, California.

50 reprints of each article are furnished free of charge; additional copies may be obtained at cost in multiples of 50 .

The Pacific Journal of Mathematics is published quarterly, in March, June, September, and December. The price per volume (4 numbers) is $\$ 12.00$; single issues, $\$ 3.50$; back numbers (Volumes $1,2,3$ ) are available at $\$ 2.50$ per copy. Special price to individual faculty members of supporting institutions and to individual members of the American Mathematical Society: $\$ 4.00$ per volume; single issues, $\$ 1.25$.

Subscriptions, orders for back numbers, and changes of address should be sent to the publishers, University of California Press, Berkeley 4, California.

Printed at Ann Arbor, Michigan. Entered as second class matter at the Post Office, Berkeley, California.

* To be succeeded in 1955, by H.L. Royden, Stanford University, Stanford, California.

** To be succeeded in 1955, by E.G. Straus, University of California, Los Angeles 24, Calif.

UNIVERSITY OF CALIFORNIA PRESS - BERKELEY AND LOS ANGELES

COPYRIGHT 1954 BY PACIFIC JOURNAL OF MATHEMATICS 


\section{Pacific Journal of Mathematics}

\section{Vol. 1, No. $4 \quad, 1951$}

R. H. Bruck, Loops with transitive automorphism groups ............ 481

Paul R. Garabedian, A partial differential equation arising in conformal

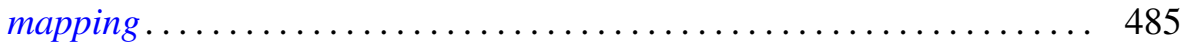

Magnus R. Hestenes, Applications of the theory of quadratic forms in Hilbert space to the calculus of variations .................. 525

Sze-Tsen Hu, On the realizability of homotopy groups and their operations ..................................... 583 